\title{
Normogram of Middle Cerebral Artery Doppler Indexes and Cerebroplacental Ratio at 12 to 14 Weeks in an Unselected Pregnancy Population
}

\author{
Reem S. Abu-Rustum, MD, FACOG, FACS, FAIUM ${ }^{1}$ \\ Nabil Helou, MD ${ }^{4}$ \\ ${ }^{1}$ Division of Maternal Fetal Medicine, Department of Obstetrics and \\ Gynecology, University of Florida, Gainesville, Florida \\ 2 Faculty of Public Health, Lebanese University, Tripoli, Lebanon \\ 3 Department of Radiology, Lebanese University, Beirut, Lebanon \\ ${ }^{4}$ Department of Radiology, Aboujaoude Hospital, Jal El Dib, Lebanon
}

\author{
M. Fouad Ziade, $\mathrm{PhD}^{2}$ Ibrahim Ghosn, MD ${ }^{3}$
}

Am J Perinatol 2019;36:155-160.

\begin{abstract}
Address for correspondence Reem S. Abu-Rustum, MD, FACOG, FACS, FAIUM, Division of Maternal Fetal Medicine, Department of Obstetrics \& Gynecology, University of Florida, Box 100294, Gainesville, FL 32610 (e-mail: rar@cfafc.org).
\end{abstract}

\begin{abstract}
Keywords

- middle cerebral artery

- first trimester scan

- pulsatility index

- peak systolic velocity

- cerebroplacental ratio
\end{abstract}

Objective The aim of this study is to assess the feasibility of visualizing the middle cerebral artery (MCA), establishing the normogram for MCA pulsatility index (PI) and peak systolic velocity (PSV), and calculating cerebroplacental ratio (CPR) at 12 to 14 weeks.

Study Design Prospective cross-sectional study on 186 gravidas presenting for nuchal translucency (NT) assessment. Maternal body mass index (BMI), fetal crown-rump length (CRL), biparietal diameter (BPD), and NT were obtained. Color Doppler was utilized to visualize the MCA and measure PI, PSV, and umbilical artery PI. Normograms for MCA PI and PSV, and for CPR, were constructed. Regression analysis was used for the reference range of MCA PI and CPR according to CRL and BPD. Chi-square and $t$-test were utilized. $p$-Value of $<0.05$ was considered significant.

Results MCA was successfully visualized in 176/186 (94.6\%), PI and PSV measured on 148/186 (79.6\%) and 145/186 (78.0\%), respectively, and CPR calculated in 133/186 (71.5\%). There was no significant effect of BMI, CRL, or BPD on successful assessment of MCA or CPR. Normograms for MCA PI and CPR revealed no significant relation with CRL or BPD.

Conclusion MCA and CPR assessment is feasible at 12 to 14 weeks. A reference range for MCA Doppler indexes and CPR at 12 to 14 weeks has been established. This may prove helpful in the early evaluation of fetuses identified as at-risk for adverse neonatal outcome.
With the technological advances and the rise in the role of a full fetal anatomic scan at the time of nuchal translucency (NT) assessment, ${ }^{1,2}$ there has been an increase in emerging data on various screening markers, particularly those for the early detection of congenital heart defects (CHDs): NT, tricuspid regurgitation, ductus venosus flow, and most recently the cardiac axis. ${ }^{3-9}$ Recent studies suggest that the brain sparing effect, first described in CHD by Donofrio et $a{ }^{10}{ }^{10}$ may be evident as early as the first trimester in fetuses with CHD. We have previously shown that fetuses with $\mathrm{CHD}$, particularly those with hypoplastic left heart syndrome, may manifest a decrease in head volume as early as the first trimester. ${ }^{11}$ This may potentially imply impaired neurodevelopment.

The earliest studies on the fetal cerebral circulation, by Wladimiroff et al in 1986, provided evidence in support of the presence of the brain sparing effect in case of fetal hypoxemia. ${ }^{12}$ Since then, several studies have evaluated the fetal circulation, as early as 10 weeks: in the 1990s, Wladimiroff et al evaluated fetal arterial flow velocities ${ }^{13,14}$ and fetal heart rate and flow velocity variability; ${ }^{15}$ in 2002 , Matias et al performed full first trimester fetal hemodynamic evaluation; ${ }^{16}$ in 2007, Tongsong et al established the peak received

November 7, 2017

accepted after revision

May 21, 2018

published online

July 6, 2018
Copyright (c) 2019 by Thieme Medical Publishers, Inc., 333 Seventh Avenue, New York, NY 10001, USA. Tel: +1(212) 584-4662.
DOI https://doi.org/ 10.1055/s-0038-1661404. ISSN $0735-1631$. 
systolic velocity (PSV) of the middle cerebral artery (MCA) in healthy fetuses between 11 and 22 weeks, ${ }^{17}$ and Rujiwetpongstorn and Phupong evaluated Doppler indexes of the MCA in healthy fetuses at 11 to 20 weeks. ${ }^{18}$

The cerebroplacental ratio (CPR) is the ratio of the pulsatility index (PI) of the MCA to the PI of the umbilical artery (UA). It was first described by Gramellini et al in 1992 as a more sensitive predictor of adverse perinatal outcome, at 30 to 41 weeks, with an accuracy of $90 \%$ when compared with either the MCA $(78.8 \%)$ or UA (83.3\%). ${ }^{19}$ The CPR reflects acute changes in partial pressure of oxygen. ${ }^{20}$ In 2003, Baschat and Gembruch reevaluated the CPR in normal fetuses between 20 and 40 weeks of gestation and constructed the reference ranges. ${ }^{20}$ To date, we are not aware of the availability of reference values for the CPR in the first trimester. As such, this study was designed to assess the feasibility of visualizing the MCA, establishing the normogram for MCA PI and PSV, and developing CPR normograms at 12 to 14 weeks of gestation in an unselected pregnancy population.

\section{Study Design}

This was a prospective cross-sectional study, approved by the Institutional Review Board, on 200 gravidas with spontaneous conception of singleton gestations, presenting for NT assessment between $12 \mathrm{w} 0 \mathrm{~d}$ and $13 \mathrm{w} 6 \mathrm{~d}$ at two centers in Lebanon and with an NT $<95$ th centile for gestational age. All patients were properly dated by an early scan. Maternal body mass index (BMI), fetal crown-rump length (CRL), biparietal diameter (BPD), and NT were measured. At our centers, a full anatomic scan is performed at the time of NT assessment. Fetuses with any structural abnormalities, in utero fetal demise, and those without a confirmed outcome of a healthy neonate were excluded from the analysis. All exams were performed transabdominally by two experienced sonologists using 4 to $8 \mathrm{MHz}$ convex high-resolution probes with twodimensional and three-dimensional capabilities (GE Voluson E8 ultrasound systems, Kretz, Zimpf, Austria). For the identification of the MCA, the plane of BPD, caudal to the thalamus, was obtained and first trimester cardiac presents, using color Doppler with high-definition flow, were utilized (- Fig. 1).

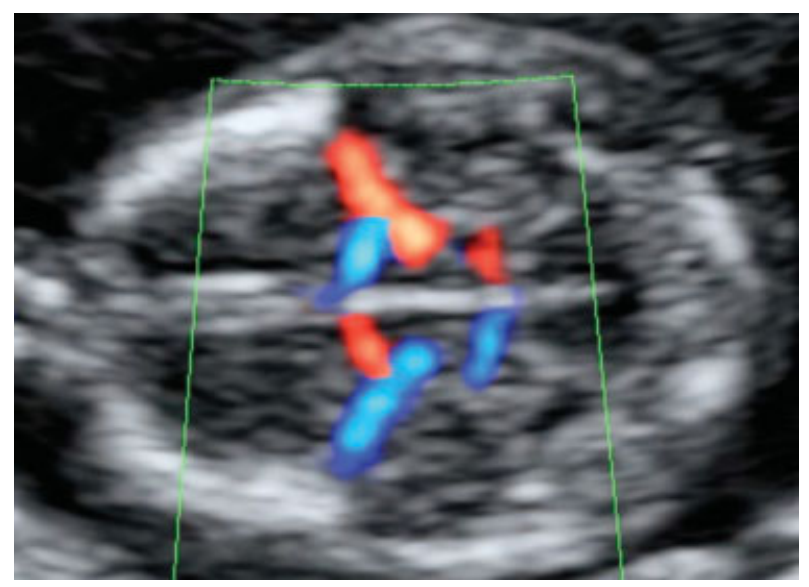

Fig. 1 Circle of Willis.
Subsequently, the MCA PI and PSV were measured at the proximal one-third of the MCA with an angle of insonation of $<10^{\circ}$. The UA was identified, using the same presets and color Doppler with high-definition flow, and the PI was measured in a free loop of cord. We employed the As Low As Reasonably Achievable principle ${ }^{21}$ maintaining a thermal index of $<1$ and minimizing scanning time with color and pulse wave Doppler to less than 2 minutes as per the American Institute of Ultrasound in Medicine ${ }^{22}$ and International Society of Ultrasound in Obstetrics \& Gynecology ${ }^{23}$ safety recommendations. The CPR was calculated as the ratio of the PI of the MCA to the PI of the UA. The normograms for the MCA PI and CPR were constructed. Regression analysis approach and different polynomial degrees (second and third) were used to study the reference range of the MCA PI and CPR according to CRL and BPD. The normogram for the MCA PSV was determined using crude data and compared with what has been established in a Thai population. Chi-square and $t$-test were utilized. A $p$-value of $<0.05$ was considered significant.

\section{Results}

A total of 186 fetuses were included in our final analysis (-Fig. 2). Maternal and fetal characteristics are summarized in - Table 1 . The MCA was successfully visualized in 176/186 (94.6\%) of fetuses. The MCA PI and PSV were obtained on $148 / 186$ (79.6\%) and 145/186 (78.0\%) fetuses, respectively.

There was no significant effect of maternal BMI, fetal CRL, or BPD on successful visualization of the MCA (- Table 2). The normogram for the MCA PI in our population was established according to gestational age as well as CRL categories (- Table 3). The mean PI values at a gestational age of 12 weeks (2.56) and at 13 weeks (2.37) obtained in this study were comparable with previously published data by Rujiwetpongstorn and Phupong in $2007^{18}$ at a gestational age of 12 weeks (2.55) and at 13 weeks (2.30) with no significant difference ( $p=0.999$ and $p=0.630$, respectively). The reference range of the MCA PI according to CRL ( - Fig. 3 ) and BPD ( - Fig. 4) was determined. There was no significant relation between MCA PI with CRL $(p=0.065)$ and between MCA PI with BPD $(p=0.195)$, with a best fitted linear regression modeling yield of: MCA PI $=3.541$ to $0.017 \mathrm{CRL}\left(R^{2}=0.023\right)$ and MCA PI $=2.57$ to 0.00653 .182 to $0.035 \mathrm{BPD}\left(R^{2}=0.011\right)$, respectively. The normogram for the MCA PSV in our population was established and it was comparable to what has previously been published by Tongsong et al $^{17}$ and Rujiwetpongstorn and Phupong ${ }^{18}$ (- Fig. 5).

The UA was successfully measured and CPR calculated in $133 / 186$ (71.5\%) of cases. The normogram for the CPR in our population was established according to the gestational age as well as CRL categories (-Table 4), and the reference range of the CPR according to CRL ( - Fig. 6) and BPD (-Fig. 7) was determined. There was no significant effect of BMI, CRL, or BPD on successful assessment of the CPR (-Table 5). In addition, there was no significant relation between CPR and CRL $(p=0.778)$, or CPR with BPD $(p=0.130)$, with a best fitted linear regression modeling yield of: $\mathrm{CPR}=0.832$ to $0.002 \mathrm{CRL}\left(R^{2}=0.023\right)$ and $\mathrm{CPR}=0.285$ to $0.031 \mathrm{BPD}$ $\left(R^{2}=0.130\right)$, respectively. 


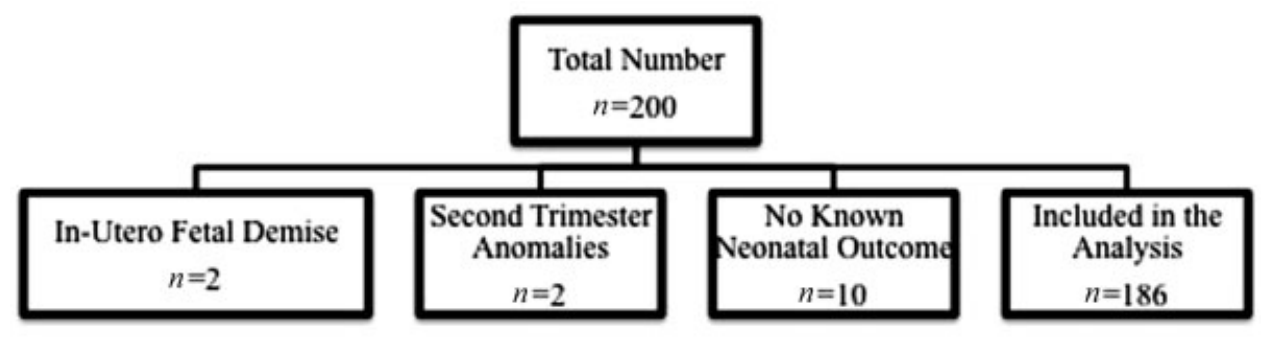

Fig. 2 Flowchart of data collection for fetal inclusion in the study.

\section{Discussion}

As our data demonstrate, it is possible to visualize the MCA in $176 / 186$ (94.6\%) of cases at the time of NT assessment. There seems to be no impact of maternal BMI, fetal CRL, or BPD on successful visualization, keeping in mind the low BMI in our patient population (mean, $24.5 \mathrm{~kg} / \mathrm{m}^{2}$ ).

We have been able to establish the normogram for the MCA PI at 12 to 14 weeks in our unselected pregnancy population (-Table 3 ). In addition, we have established the normogram for the MCA PSV and it is comparable to what has already been established by Tongsong et al and Rujiwetpongstorn and Phupong in a Thai population ${ }^{17,18}$ (-Fig. 5). There is no significant relationship between MCA PI and fetal CRL or BPD. It is important to note that there has been inconsistency in various studies as to where the MCA Doppler indexes are measured: we chose the proximal one-third as did both Tongsong et al and Rujiwetpongstorn and Phupong in a Thai population. ${ }^{17,18}$ This was not the case in the second trimester with Baschat and Gembruch. ${ }^{20}$

The CPR was successfully calculated in 133/186 (71.5\%) of cases and the normogram established. As with the MCA PI,

Table 1 Maternal and fetal characteristics

\begin{tabular}{|c|l|l|l|}
\hline & $N$ & Mean & Standard deviation \\
\hline Maternal parameters \\
\hline BMI $\left(\mathrm{kg} / \mathrm{m}^{2}\right)$ & 186 & 24.66 & 4.34 \\
\hline Fetal parameters \\
\hline CRL $(\mathrm{mm})$ & 186 & 68.12 & 7.41 \\
\hline BPD $(\mathrm{mm})$ & 186 & 22.13 & 2.52 \\
\hline NT $(\mathrm{mm})$ & 186 & 1.70 & 0.41 \\
\hline
\end{tabular}

Abbreviations: BMI, body mass index; BPD, biparietal diameter;

CRL, crown-rump length; GA, gestational age; NT, nuchal translucency. there was no significant relationship between the CPR and fetal CRL or BPD. This is consistent with what has been shown in the second trimester by Baschat and Gembruch: ${ }^{20}$ our data show that the CPR is not constant between 12 and 14 weeks. In contrast to a CPR greater than 1.08 in second trimester normal fetuses, ${ }^{20}$ the CPR may be less than 1 at 12 to 14 weeks ( - Table 4). This may be attributed to the high UA PI in early gestation and the typical absence of end-diastolic flow prior to 13 weeks. ${ }^{16}$ By a gestational age of 13 weeks, the 50th centile for the CPR approaches 1 (-Table 4). As such, the examiner should be mindful to the fact that the CPR tends to be less than 1 in normal fetuses prior to 13 weeks.

The strength of our study is that it is prospective in nature and we have a large cohort of patients: 186 patients at 12 to 14 weeks with a confirmed outcome of a normal neonate in comparison to prior studies involving first trimester fetuses. The two previous studies in a Thai population included 410 and 149 patients, respectively; however, they were spread out between 11 and 22 weeks. $^{17,18}$

Table 3 Normogram of calculated MCA PI at the 5th, 10th, 50th, 90th, and 95th percentiles for each gestational age

\begin{tabular}{|l|l|l|l|l|l|}
\hline \multirow{2}{*}{ GA (wk) } & \multicolumn{5}{l}{ MCA PI } \\
\cline { 2 - 6 } & 5th & 10th & 50th & 90th & 95th \\
\hline 12 & 1.00 & 1.26 & 2.56 & 3.40 & 3.49 \\
\hline 13 & 1.00 & 1.35 & 2.37 & 3.22 & 3.53 \\
\hline CRL categories \\
\hline$<65 \mathrm{~mm}$ & 0.97 & 1.07 & 2.50 & 3.41 & 3.72 \\
\hline$[65-70] \mathrm{mm}$ & 1.39 & 1.52 & 2.74 & 3.41 & 3.57 \\
\hline$[70-75] \mathrm{mm}$ & 1.00 & 1.00 & 2.47 & 3.42 & 3.54 \\
\hline$\geq 75 \mathrm{~mm}$ & 1.03 & 1.32 & 2.22 & 3.14 & 3.45 \\
\hline
\end{tabular}

Abbreviations: CRL, crown-rump length; GA, gestational age; MCA, middle cerebral artery; PI, pulsatility index.

Table 2 Successful visualization of MCA by maternal and fetal parameters

\begin{tabular}{|l|l|l|l|l|l|l|l|}
\hline & \multicolumn{2}{|l}{ MCA not seen } & \multicolumn{2}{l|}{ MCA seen } & \multirow{2}{*}{$\boldsymbol{p}$-Value } \\
\cline { 2 - 9 } & $N$ & Mean & Standard deviation & $N$ & Mean & Standard deviation & \\
\hline Maternal BMI & 38 & 24.80 & 4.85 & 148 & 24.62 & 4.21 & 0.826 \\
\hline Fetal CRL $(\mathrm{mm})$ & 38 & 67.93 & 7.37 & 148 & 68.17 & 7.44 & 0.856 \\
\hline Fetal BPD $(\mathrm{mm})$ & 38 & 21.76 & 2.60 & 148 & 22.22 & 2.50 & 0.315 \\
\hline
\end{tabular}

Abbreviations: BMI, body mass index; BPD, biparietal diameter; CRL, crown-rump length; GA, gestational age; MCA, middle cerebral artery. 


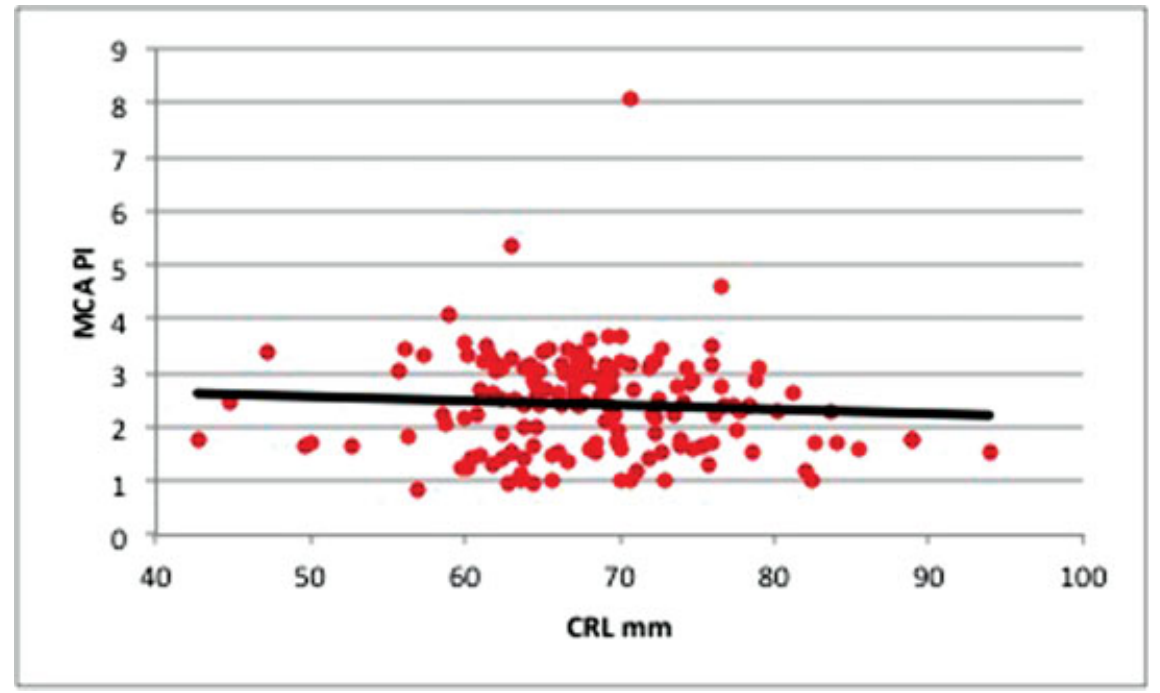

Fig. 3 Regression analysis of the middle cerebral artery (MCA) pulsatility index (PI) by crown-rump length (CRL).

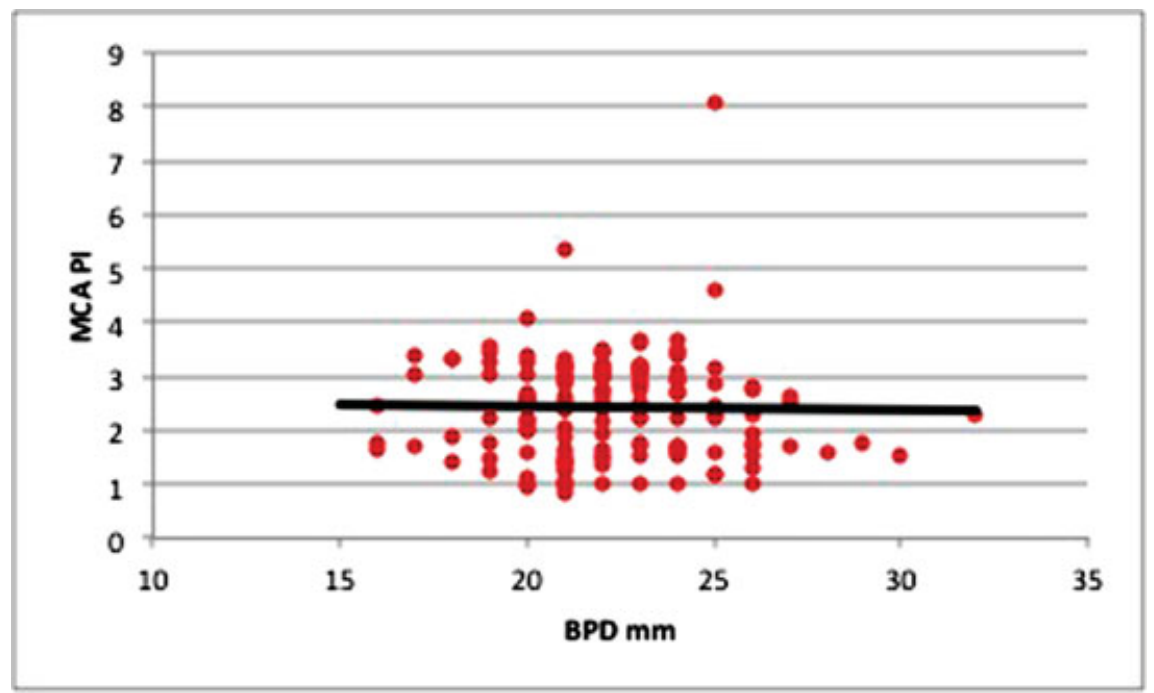

Fig. 4 Regression analysis of the middle cerebral artery (MCA) pulsatility index (PI) by biparietal diameter (BPD).

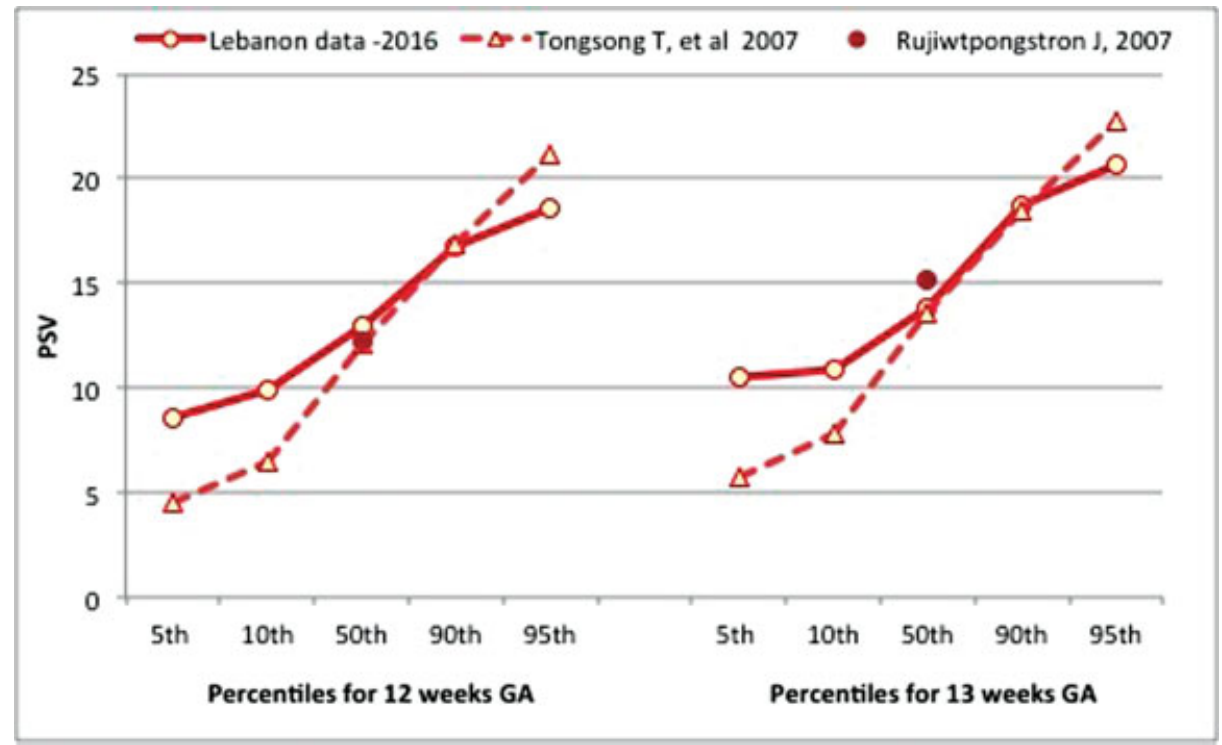

Fig. 5 The normogram for middle cerebral artery (MCA) peak systolic velocity (PSV) by gestational age (GA) in comparison with Tongsong et al and Rujiwetpongstorn and Phupong. 
MCA Doppler Indexes and CPR at 12 to 14 Weeks Abu-Rustum et al. 159

Table 4 Normogram of calculated CPR at the 5th, 10th, 50th, 90th, and 95th percentiles for each gestational age and CRL categories

\begin{tabular}{|l|l|l|l|l|l|}
\hline \multirow{2}{*}{ GA (wk) } & \multicolumn{5}{l}{ CPR } \\
\cline { 2 - 6 } & 5th & 10th & 50th & 90th & 95th \\
\hline 12 & 0.17 & 0.29 & 0.81 & 1.69 & 1.96 \\
\hline 13 & 0.23 & 0.35 & 0.98 & 1.94 & 2.23 \\
\hline CRL categories \\
\hline$<65 \mathrm{~mm}$ & 0.15 & 0.32 & 0.80 & 1.81 & 2.19 \\
\hline$[65-70[\mathrm{~mm}$ & 0.16 & 0.23 & 0.92 & 1.96 & 2.29 \\
\hline$[70-75[\mathrm{~mm}$ & 0.29 & 0.36 & 0.75 & 1.99 & 3.17 \\
\hline$\geq 75 \mathrm{~mm}$ & 0.39 & 0.48 & 0.98 & 1.62 & 1.74 \\
\hline
\end{tabular}

Abbreviations: CPR, cerebroplacental ratio; CRL, crown-rump length; $\mathrm{GA}$, gestational age.
Table 5 Successful calculation of CPR by maternal and fetal parameters

\begin{tabular}{|l|c|l|l|l|l|l|l|}
\hline & \multicolumn{3}{|l|}{ CPR not calculated } & \multicolumn{2}{l|}{ CPR calculated } & \multirow{2}{*}{$p$-Value } \\
\cline { 2 - 7 } & $N$ & Mean & $\begin{array}{l}\text { Standard } \\
\text { deviation }\end{array}$ & $N$ & Mean & $\begin{array}{l}\text { Standard } \\
\text { deviation }\end{array}$ & \\
\hline $\begin{array}{l}\text { Maternal } \\
\text { BMI } \\
\left(\mathrm{kg} / \mathrm{m}^{2}\right)\end{array}$ & 53 & 24.68 & 4.57 & 133 & 24.65 & 4.26 & 0.968 \\
\hline $\begin{array}{l}\text { Fetal } \\
\text { CRL, } \\
\mathrm{mm}\end{array}$ & 53 & 68.27 & 7.16 & 133 & 68.07 & 7.53 & 0.866 \\
\hline $\begin{array}{l}\text { Fetal } \\
\text { BPD, } \\
\mathrm{mm}\end{array}$ & 53 & 22.04 & 2.54 & 133 & 22.16 & 2.52 & 0.781 \\
\hline
\end{tabular}

Abbreviations: BMI, body mass index; BPD, biparietal diameter; CPR, cerebroplacental ratio; CRL, crown-rump length.

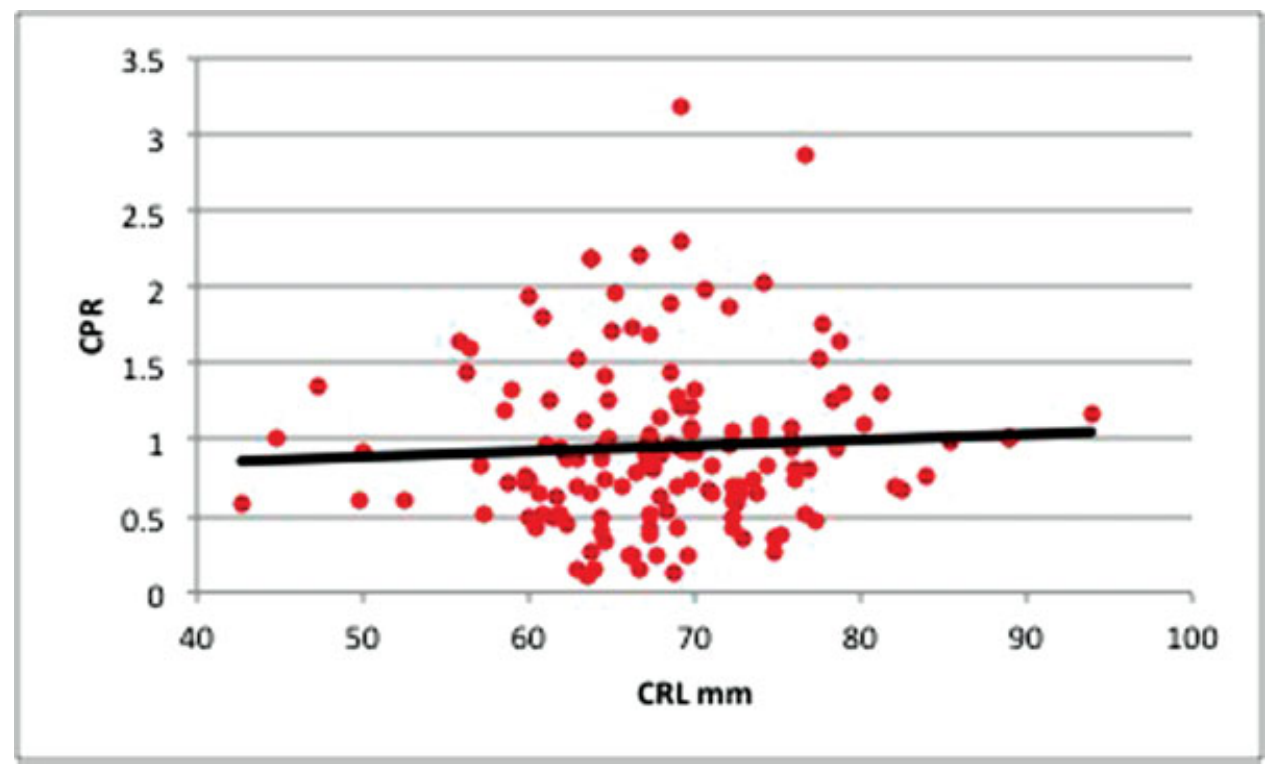

Fig. 6 Regression analysis of cerebroplacental ratio (CPR) by crown-rump length (CRL).

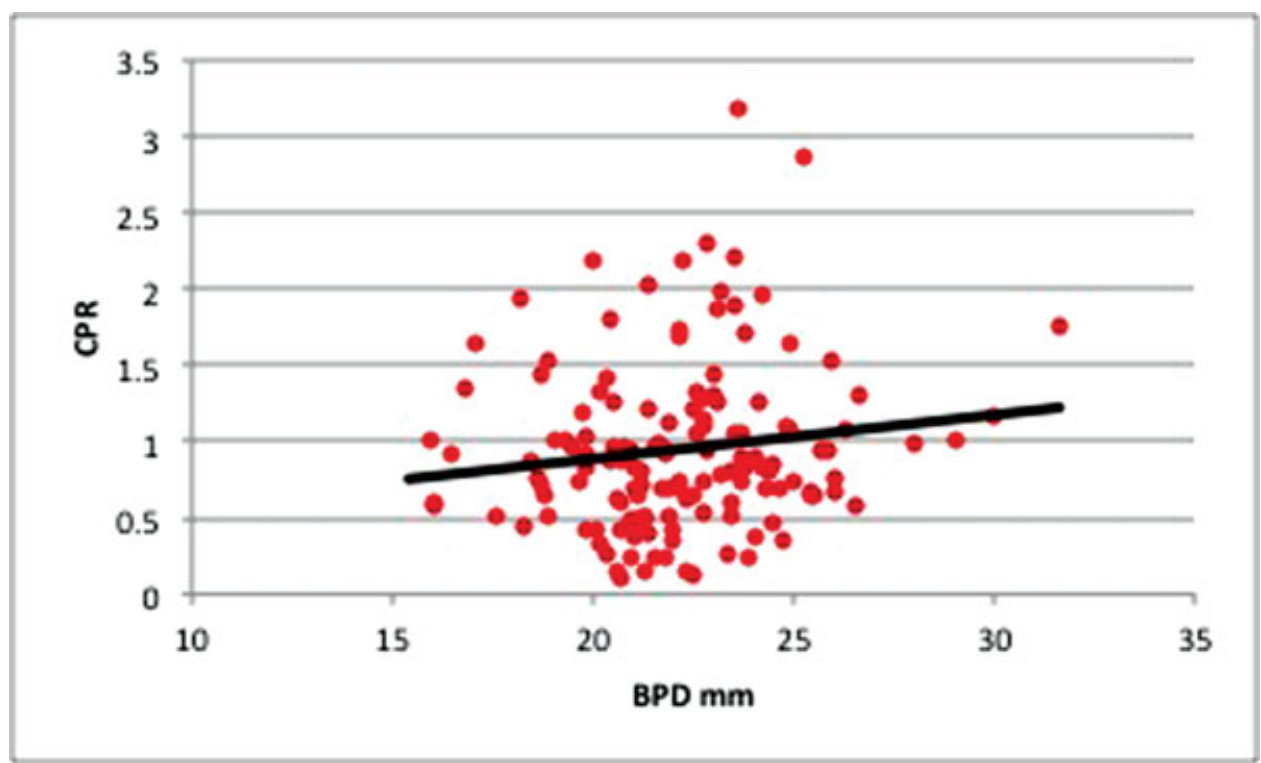

Fig. 7 Regression analysis of cerebroplacental ratio (CPR) by biparietal diameter (BPD). 
In addition, our data are further validated by the fact that with our larger numbers, the results in our unselected Lebanese population are comparable to what has already been established with respect to both the MCA PI and PSV in a Thai population. It is noteworthy that both studies from Thailand, as ours, were cross-sectional studies. ${ }^{17,18}$

Our study has several limitations. Given Doppler indexes at the proximal one-third of the MCA are less likely to be affected by fetal behavioral status as described by Clerici et al in $2002,{ }^{24}$ we chose to measure the MCA Doppler indexes at the proximal one-third of the MCA, an area where they may be lower than at the middle and distal third. ${ }^{25}$ Furthermore, we did not evaluate maternal uterine artery Doppler indexes and their potential effect on fetal perfusion and the CPR.

In conclusion, MCA evaluation is feasible at the time of NT assessment. To our knowledge, our study is the first to provide a reference range for first trimester CPR at 12 to 14 weeks. Having established normograms for MCA Doppler indexes and CPR at 12 to 14 weeks may prove helpful, when indicated, in the early assessment of at-risk fetuses identified by abnormal uterine artery Doppler studies, maternal risk factors, those at risk for anemia, growth restriction, and impending demise, among others. Larger prospective studies are needed to examine the potential role of the MCA Doppler indexes and CPR as first trimester modalities in the evaluation of fetuses at risk for adverse neonatal outcome.

\section{Note}

This article has been presented as two oral abstract presentations at the AIUM Annual Convention in Orlando, Florida, in March 2017.

\section{Conflict of Interest}

None.

\section{References}

1 Abu-Rustum RS, Daou L, Abu-Rustum SE. Role of first-trimester sonography in the diagnosis of aneuploidy and structural fetal anomalies. J Ultrasound Med 2010;29(10):1445-1452

2 Rossi AC, Prefumo F. Accuracy of ultrasonography at 11-14 weeks of gestation for detection of fetal structural anomalies: a systematic review. Obstet Gynecol 2013;122(06):1160-1167

3 Hyett JA, Perdu M, Sharland GK, Snijders RS, Nicolaides KH. Increased nuchal translucency at 10-14 weeks of gestation as a marker for major cardiac defects. Ultrasound Obstet Gynecol 1997;10(04):242-246

4 Hyett J, Perdu M, Sharland G, Snijders R, Nicolaides KH. Using fetal nuchal translucency to screen for major congenital cardiac defects at 10-14 weeks of gestation: population based cohort study. BMJ 1999;318(7176):81-85

5 Matias A, Huggon I, Areias JC, Montenegro N, Nicolaides KH. Cardiac defects in chromosomally normal fetuses with abnormal ductus venosus blood flow at 10-14 weeks. Ultrasound Obstet Gynecol 1999;14(05):307-310

6 Timmerman E, Clur SA, Pajkrt E, Bilardo CM. First-trimester measurement of the ductus venosus pulsatility index and the prediction of congenital heart defects. Ultrasound Obstet Gynecol 2010;36(06):668-675
7 Pereira S, Ganapathy R, Syngelaki A, Maiz N, Nicolaides KH. Contribution of fetal tricuspid regurgitation in first-trimester screening for major cardiac defects. Obstet Gynecol 2011;117 (06):1384-1391

8 Sotiriadis A, Papatheodorou S, Eleftheriades M, Makrydimas G. Nuchal translucency and major congenital heart defects in fetuses with normal karyotype: a meta-analysis. Ultrasound Obstet Gynecol 2013;42(04):383-389

9 Sinkovskaya ES, Chaoui R, Karl K, Andreeva E, Zhuchenko L, Abuhamad AZ. Fetal cardiac axis and congenital heart defects in early gestation. Obstet Gynecol 2015;125(02):453-460

10 Donofrio MT, Bremer YA, Schieken RM, et al. Autoregulation of cerebral blood flow in fetuses with congenital heart disease: the brain sparing effect. Pediatr Cardiol 2003;24(05):436-443

11 Abu-Rustum RS, Ziade MF, Abu-Rustum SE, Daou LS. Are there head volume alterations at 11-14 weeks in fetuses with congenital heart defects? A first trimester case series. AJP Rep 2016;6 (02):e232-e238

12 Wladimiroff JW, Tonge HM, Stewart PA. Doppler ultrasound assessment of cerebral blood flow in the human fetus. $\mathrm{Br} \mathrm{J}$ Obstet Gynaecol 1986;93(05):471-475

13 Wladimiroff JW, Huisman TW, Stewart PA. Fetal and umbilical flow velocity waveforms between 10-16 weeks' gestation: a preliminary study. Obstet Gynecol 1991;78(5 Pt 1):812-814

14 van Splunder P, Huisman TW, DeRidder MA, Wladimiroff JW. Fetal venous arterial flow velocity waveforms between 8 and 20 weeks of gestation. Pediatr Res 1996;40:158-162

15 Ursem NTC, Struijk PC, Hop WCJ, Clark EB, Keller BB, Wladimiroff JW. Heart rate and flow velocity variability as determined from umbilical Doppler velocimetry at 10-20 weeks of gestation. Clin Sci (Lond) 1998;95(05):539-545

16 Matias A, Montenegro N, Areias JC, Leite LP. Haemodynamic evaluation of the first trimester fetus with special emphasis on venous return. Hum Reprod Update 2000;6(02):177-189

17 Tongsong T, Wanapirak C, Sirichotiyakul S, Tongprasert F, Srisupundit K. Middle cerebral artery peak systolic velocity of healthy fetuses in the first half of pregnancy. J Ultrasound Med 2007;26 (08):1013-1017

18 Rujiwetpongstorn J, Phupong V. Doppler waveform indices of the middle cerebral artery of normal fetuses in the first half of pregnancy in the Thai population. Arch Gynecol Obstet 2007;276(04):351-354

19 Gramellini D, Folli MC, Raboni S, Vadora E, Merialdi A. Cerebralumbilical Doppler ratio as a predictor of adverse perinatal outcome. Obstet Gynecol 1992;79(03):416-420

20 Baschat AA, Gembruch U. The cerebroplacental Doppler ratio revisited. Ultrasound Obstet Gynecol 2003;21(02):124-127

21 Official Statement AIUM. As Low As Reasonably Achievable (ALARA) Principle. Approved 3/16/2008; Reapproved 4/2/2014. Available at: http://www.aium.org/officialStatements/39. Accessed June 5, 2018

22 Official Statement AIUM. Statement on the Safe Use of Doppler Ultrasound During 11-14 week scans (or earlier in pregnancy). Approved 4/18/2011; Revised 3/21/2016, 10/30/2016. Available at: http://www.aium.org/officialStatements/42. Accessed June 5, 2018

23 Salvesen K, Lees C, Abramowicz J, Brezinka C, Ter Haar G, Maršál K. ISUOG statement on the safe use of Doppler in the 11 to $13+6$ week fetal ultrasound examination. Ultrasound Obstet Gynecol 2011;37:628-628

24 Clerici G, Luzietti R, Cutuli A, Direnzo GC. Cerebral hemodynamics and fetal behavioral states. Ultrasound Obstet Gynecol 2002;19 (04):340-343

25 Hsieh YY, Chang CC, Tsai HD, Tsai CH. Longitudinal survey of blood flow at three different locations in the middle cerebral artery in normal fetuses. Ultrasound Obstet Gynecol 2001;17(02):125-128 